\title{
PERANAN TRANSFORMATIONAL LEADERSHIP UNTUK MENGURANGI KONFLIK DALAM HUBUNGAN KEAGENAN
}

\author{
Nur Fadjih Asyik \\ Sekolah Tinggi Ilmu Ekonomi Indonesia Surabaya
}

\begin{abstract}
Principal-agent framework has paradigm used widely in accounting and economic to analize issues about performance evaluation, management controlling, and incentive system design (Jensen and Meckling, 1976). Due to leadership, agency relationship delegate power from leader to subordinate. Leader control subordinate's performance with accountability mechanism. Another side, there is uncertainty in the business environment. Due to with this condition, vision is needed in order to there is a better change. Organization which can survive and growth is organization has leader with the vision to do changing sharply so leader able transformate organization capabilities to build competitive advantage of the firm (Kotter, 1996). Due to conflict of interest between leader and subordinate in agency relationship, transformational leadership style is convinced able to direct to superior performance in organization with four ways are idealized influence, inspirational motivation, intellectual stimulation, and individualized concideration (Bass and Avolio, 1994).
\end{abstract}

Keywords: transformational leadership, agency relationship

\section{PENDAHULUAN}

Dunia bisnis saat ini sedang memasuki realitas baru. Globalisasi dan kemajuan teknologi telah menciptakan lingkungan persaingan baru yang sangat dinamis. Banyak perusahaan kelas dunia dibikin repot oleh perubahan lingkungan bisnis yang turbulance (bergejolak) dan uncertainty (tidak pasti). Faktor-faktor lingkungan usaha yang bergejolak dan berubah ini menjadikan masa depan tidak pasti dan bergejolak. Masa depan merupakan masa yang penuh persaingan. Untuk menghadapi masa depan yang penuh persaingan dibutuhkan organisasi yang dapat membuat pergeseran dari hanya sekedar menyebarkan informasi di sekitar jaringan kerja kepada organisasi yang dapat menerima dan menanggapi perubahan yang cepat dalam pasar, teknologi, kompetisi dan kebutuhan konsumen. Organisasi yang dibutuhkan dimasa mendatang adalah organisasi yang dapat mengatur dirinya untuk penciptaan perusahaan masa depan.

Hammer (1992) berpendapat bahwa satu-satunya cara untuk mengubah struktur organisasi yang ada pada masa lalu dengan struktur organisasi yang memungkinkan kita beradaptasi dengan masa depan adalah dengan mengubah seluruh model organisasi pada masa lalu beserta asumsi-asumsi yang mendasarinya. Organisasi yang dapat memenangkan persaingan adalah organisasi 
yang dapat menangkap di luar hal-hal yang bersifat normal dan membuat sesuatu yang berbeda. Organisasi akan berhasil bila mampu memprediksi masa depan dan bahkan mampu mengelola masa depan. Organisasi yang sukses bersaing di masa depan adalah organisasi yang mempunyai kapabilitas organizational learning, knowledge creation, dan corporate culture yang sesuai dengan strategi perusahaan. Organisasi ini membutuhkan seorang pengemudi yang dapat mengendalikan arah yang akan dituju.

Diantara pihak-pihak tersebut, terdapat pertentangan kepentingan antara kelompok internal (manajemen) dan eksternal (pemegang saham, kreditor, dan pemerintah) yang dapat mendorong timbulnya konflik yang merugikan bagi pihakpihak yang bertentangan tersebut.

Makalah ini menggunakan framework principal - agent yang telah menjadi paradigma yang digunakan secara luas dalam akuntansi dan ekonomi untuk menganalisa isu-isu yang berkaitan dengan evaluasi performance, pengendalian manajemen, dan desain sistem insentif. Beberapa penelitian telah menguji secara empiris beberapa asumsi yang mendasari dan implikasi agency theory [lihat Baiman dan Lewis (1989)], namun tidak banyak pengujian dengan menggunakan dunia nyata atau data yang terjadinya secara natural. Yang menjadi isu dalam leadership suatu organisasi adalah seberapa baik leader dapat menetapkan insentif ke dalam kontrak untuk menjamin bahwa subordinate melakukan action sesuai dengan kepentingan leader berdasarkan level effort yang ada. Isu tersebut tidak lepas dari peran gaya leadership yang mengharapkan leader memiliki kemampuan untuk mengatasi kompleksitas, ketidakjelasan, dan ketidakpastian. Salah satunya berkaitan dengan akuntan manajemen karena insentif seringkali didasarkan pada variabel yang diukur dan dikomunikasikan oleh sistem akuntansi manajemen. Ide mengenai teori agency dapat dillustrasikan dengan sebuah contoh travelling salesperson (subordinate) dan sales manager (leader). Kontrak salesperson akan menetapkan elemen berkaitan dengan performance berdasarkan pada penjualan. Bagaimanapun, jumlah penjualan subordinate tidak dapat ditentukan secara sempurna berdasarkan level effort karena terdapat unsur ketidakpastian seperti keinginan customer. Berdasarkan event yang uncontrollable, maka skema payment yang berkaitan dengan performance menjadi subjek subordinate terhadap adanya risiko. Subordinate yang bekerja keras kadangkadang menerima pembayaran komisi yang rendah, sementara subordinate yang memberikan effort yang kecil kemungkinan memperoleh reward yang lebih banyak (Ashton, et al., 1995).

\section{TEORI AGENSI}

Hubungan keagenan, sebagaimana didefinisikan oleh Jensen dan Meckling (1976), adalah suatu kontrak antara dua pihak yang memuat pendelegasian 
pekerjaan dan wewenang oleh pihak pertama (sebagai principal/leader) kepada pihak kedua (sebagai agent/subordinate) agar pihak kedua bersedia melakukan pekerjaan tersebut untuk kepentingan pihak pertama. Dua masalah yang timbul akibat kontrak:

1. Masalah Keagenan. Masalah keagenan muncul karena perbedaan tujuan antara principal/leader dengan agent/subordinate dan mahalnya biaya bagi principal/leader untuk memeriksa apa yang dikerjakan oleh agent/subordinate.

2. Masalah Risk Sharing. Masalah risk sharing muncul karena perbedaan preferensi resiko antara principal/leader dengan agent/subordinate. Dengan demikian, leader dan subordinate menyukai tindakan yang berbeda karena perbedaan preferensi risiko.

Sesuai dengan metapor "kontrak", apa yang diupayakan dalam pendekatan ini adalah bagaimana menentukan kontrak yang paling efisien dalam mengatur hubungan antara prinsipal/leader dan agent/subordinate berdasarkan asumsi tertentu mengenai orang (self-interest, bounded rationality, dan risk aversed) dan organisasi (konflik tujuan antara anggotanya).

Dalam analisis principle-agent didasarkan anggapan bahwa para karyawan dimotivasi oleh kepentingannya sendiri daripada sikap mementingkan kepentingan orang lain. Oleh karena itu, para karyawan berusaha untuk mencapai tujuannya sendiri daripada untuk mencapai tujuan organisasi. Lagi pula, para pemilik tidak mungkin untuk selalu memantau perilaku dan tindakan-tindakan para karyawan untuk mencegah mereka mengejar tercapainya tujuan mereka sendiri. Ada asumsi yang mengemukakan sifat dasar manusia: (1) manusia pada umumnya self interest yaitu mementingkan diri sendiri dan tidak mau berkorban untuk orang lain, (2) manusia mempunyai pikiran yang terbatas atas persepsi masa datang (bounded rationality), dan (3) manusia selalu menghindari risiko yang bisa menimpa dirinya sendiri (risk averse) walaupun atas costs orang lain (Eisenhardt, 1989). Produk dari ketiadaan harmonisasi antara agen dan prinsipal adalah timbulnya ketidakseimbangan informasi (information asymmetry). Ini kemungkinan mengakibatkan adanya konflik antara prinsipal dan agen untuk saling mencoba memanfaatkan pihak lain untuk kepentingan sendiri. Dalam kondisi ini, alat untuk melindungi organisasi dari penurunan semangat kebersamaan untuk mencapai tujuan organisasi atau bahkan timbulnya anarki adalah membuat ikatan perjanjian atau kontrak antara para pemilik dengan para karyawannya. Dalam kontrak tersebut menentukan tindakan-tindakan yang harus dilaksanakan oleh para karyawan maupun balas jasa yang akan diterimanya.

Dalam Agency Theory terdapat dua pihak yang melakukan kontrak yaitu agent dan principal. Kontrak tersebut bisa dalam bentuk: (1) kontrak kerja dan (2) kontrak pinjaman. Kontrak kerja dilakukan oleh pemilik perusahaan dan top manajer 
perusahaan atau antara leader dan subordinate, sedangkan kontrak pinjaman dilakukan oleh manajer perusahaan dan pemberi pinjaman.

Wolk et al. (1992) menjelaskan bahwa agency theory perusahaan digambarkan sebagai lokus (titik temu) hubungan keagenan antara pemilik perusahaan (principal) dan manajemen perusahaan (agent) dan berusaha memberi suatu pemahaman perilaku organisasional dengan mengungkapkan bagaimana pihakpihak yang terlibat dalam hubungan keagenan dalam perusahaan berusaha untuk memaksimalkan utility mereka.

Bidang perbedaan utama antara teori dan praktek akuntansi manajemen adalah dalam alokasi-alokasi biaya. Saat ini perdebatan mengenai alokasi biaya semakin memuncak. Sebagian besar pakar berpendapat bahwa pendekatan teoritik dan praktek untuk mengalokasikan biaya adalah tidak relevan bagi bisnis modern, khususnya bisnis yang menggunakan teknologi pemanufakturan berdasar komputer. Perdebatan mengenai alokasi biaya ini mulai timbul dari perlakuan biaya modal untuk perusahaan kereta api pada pertengahan abad ke-19 sampai akhir abad ke-20 (sekarang) untuk menentukan biaya produk secara individual pada perusahaan manufaktur yang beroperasi dengan menggunakan robot-robot. Namun, dalam praktek, selain dipengaruhi oleh teori ekonomi, alokasi biaya dipengaruhi oleh faktorfaktor hukum, politik, dan sosial. Konsekuensinya, para periset harus peka terhadap keadaan-keadaan organisasi dan sosial untuk digunakan dalam pengalokasian biaya (Supriyono, 1997).

Jensen dan Meckling (1976) mendefinisikan agency cost sebagai penjumlahan dari tiga komponen berikut:

1. Monitoring Expenditure oleh Principal

Adalah pengeluaran principal untuk mengubah peluang manajer (agent) untuk menikmati non pecuniary benefit (contoh: biaya untuk mengukur dan mengawasi tindakan agent, biaya menyusun kebijakan kompensasi, dan lain-lain).

2. Bonding expenditure oleh agent

Adalah pengeluaran manajer (agent) untuk memberikan jaminan kepada principal bahwa agent tidak akan melakukan aktivitas yang dapat merugikan perusahaan (contoh: kesediaan manajer untuk menyewa auditor untuk mengaudit laporan keuangan perusahaannya, kesediaan manajer untuk terikat pada kontrak dengan principal yang mencakup pembatasan terhadap wewenang manajer untuk mengambil keputusan dan lain sebagainya).

3. Residual loss

Tindakan yang dilakukan agent akan berbeda dengan tindakan yang dilakukan principal, Jensen dan Mackling mendefinisikan perbedaan dalam tindakan ini sebagai residual loss. 
Berkaitan dengan leadership, hubungan antara principal (leader) dan agent (subordinate) berkaitan dengan akuntansi keuangan karena kontrak antara principal dan agent sering berdasar pada pelaporan keuangan perusahaan, misalnya pemberian bonus berdasarkan atas laba bersih perusahaan, dan pemberian pinjaman berdasarkan rasio utang terhadap ekuitas (debt to equity) minimal perusahaan. Sebagaimana dinyatakan oleh beberapa peneliti bahwa angka akuntansi merupakan bagian integral dari kontrak formal dan informal perusahaan (Christie dan Zimmerman, 1994).

Jensen dan Murphy (1990) dan Lambert dan Larcker (1987) dalam Healy dan Palepu (1993) menyatakan bahwa sebagian besar penentuan kompensasi eksekutif adalah laba. Warner et al. (1988) dan Weisbach (1988) dalam Healy dan Palepu (1993) menunjukkan bahwa kemungkinan besar perusahaan akan mengganti CEO-nya apabila kinerja laba perusahaan jelek.

Penelitian di atas secara empiris membuktikan bahwa hubungan antara principal dan agent sering ditentukan oleh angka akuntansi, hal ini memacu manajemen untuk memikirkan bagaimana angka akuntansi dapat lebih memaksimalkan kepentingannya. Penggunaan angka akuntansi sebagai dasar pemberian kompensasi dapat memicu manajer untuk memanfaatkan wewenang manajer memilih metoda akuntansi dan menetapkan eatimasi akuntansi untuk memaksimumkan bonus yang diperoleh (Healy, 1985).

\section{KONSEP LEADERSHIP}

Leadership adalah hubungan antara seseorang (leader) dengan orang lain (subordinate), dan leader mampu mempengaruhi subordinate agar bersedia bekerja bersama-sama dalam tugas-tugas yang berkaitan untuk mencapai tujuan yang telah ditetapkan. Sedangkan Koonz dan O'Donnell dalam Sigit (1983) mendefinisikan leadership sebagai seni membujuk subordinate agar mau mengerjakan tugas-tugas dengan yakin dan bersemangat. Selanjutnya Robbins (2001) mendefinisikan leadership sebagai kemampuan untuk mempengaruhi sekelompok orang ke arah pencapaian tujuan.

Ada tiga implikasi penting dari definisi-definisi leadership (Handoko, 1986) yaitu:

1. Leadership menyangkut orang lain, subordinate atau pengikut. Kesediaan mereka untuk menerima pengarahan dari leader dapat membantu menentukan status atau kedudukan leader dan membuat proses leadership dapat berjalan. Tanpa bawahan, semua kualitas leadership seseorang akan menjadi tidak relevan.

2. Leadership menyangkut suatu pembagian kekuasaan yang tidak seimbang diantara para leader dan anggota kelompok. Para leader memiliki wewenang 
untuk mengarahkan berbagai kegiatan para anggota kelompok, tetapi para anggota kelompok tidak dapat mengarahkan kegiatan-kegiatan leader secara langsung, meskipun dapat juga melalui sejumlah cara secara tidak seimbang.

3. Selain dapat memberikan pengarahan kepada subordinate atau pengikut, leader dapat juga menggunakan pengaruh. Dengan kata lain, leader tidak hanya dapat memerintah subordinate apa yang harus dilakukan, tetapi juga dapat mempengaruhi bagaimana subordinate melaksanakan perintahnya.

Salah satu faktor situasional yang akan semakin berpengaruh terhadap efektivitas leadership dalam dekade mendatang adalah hubungan antara leader dan subordinate. Esensi hubungan tersebut adalah interaksi antar pribadi yang berbeda motivasi dan potensi kekuasaan, termasuk di dalamnya keterampilan, dalam rangka mencapai tujuan bersama. Interaksi ini memiliki dua bentuk yaitu transactional leadership dan transformational leadership (Gibson, et al., 1991; Kreitner dan Kenicki, 1992; Stoner, 1995; Wren, 1995; Yulk, 1989).

\section{FRAMEWORK AGENCY DAN KAITANNYA DENGAN LEADERSHIP}

Globalisasi sebagai suatu fenomena dengan implikasinya yang mempengaruhi kegiatan produksi dan perdagangan telah memaksa para ilmuwan dan praktisi bisnis mengkaji ulang berbagai paradigma dan asumsi yang selama ini telah diuji kesahihannya. Dalam hal pelaksanaan perencanaan strategis, banyak pimpinan puncak perusahaan dibuat kecewa oleh parameter pemicu lingkungan bisnis yang selalu berubah dalam tempo pendek.

Transformational leadership yang didefinisikan Burns (1978) dan Bass (1985) memberikan tambahan penting pada konseptualisasi sebelumnya atas leadership. Keduanya menggambarkan leadership mempengaruhi lower-order change dan higher-order change dalam followers dan organisasi. Bass menggambarkan lower-order change dengan memandang pada leader yang memuaskan kebutuhan kini follower dan mempertahankan standar performance organisasional dengan menggunakan transactional leadership. Sebaliknya, transformational leadership melibatkan higher-order change dimana follower dihadapkan pada banyak tantangan dan pertanggungjawaban, disamping juga memberikan kontribusi kepada perubahan organisasional dan inovasi.

Dengan menggunakan pendekatan agency framework, ketidakpastian lingkungan bisnis masa depan akan mempengaruhi hubungan antara leader dan subordinate dalam organisasi. Untuk mengendalikan organisasi di masa mendatang dibutuhkan seorang leader yang memiliki gaya transformational leadership sebagai agen perubahan dan selalu memiliki visi yang kuat sehingga mampu membawa organisasi mencapai tujuannya dan memenangkan kompetisi di era globalisasi. Teori agency menekankan isu mengenai biaya pendelegasian dengan mengasumsikan 
bahwa keputusan tidak transparan, atau lebih umum mengarah pada unobservable. Bentuk paling sederhana dari keputusan unobservable adalah action oleh subordinate berkaitan dengan level effort untuk melaksanakan kontrak. Hal tersebut berkaitan dengan akuntan manajemen karena insentif seringkali didasarkan pada sistem yang diukur dan dikomunikasikan oleh sistem akuntansi manajemen. Berdasarkan event yang uncontrollable, maka skema payment yang berkaitan dengan performance menjadi subjek agent terhadap adanya risiko. Agent yang bekerja keras kadang-kadang menerima pembayaran komisi yang rendah, sementara agent yang memberikan effort yang kecil kemungkinan memperoleh reward yang lebih banyak (Ashton, et al., 1995).

\section{PENDEKATAN TEORI LEADERSHIP}

Studi leadership secara garis besar dikelompokkan ke dalam tiga pendekatan. Pertama, trait theories (pendekatan sifat) yang berupaya mengidentifikasi kombinasi ciri-ciri atau sifat tertentu yang dapat membedakan leader dengan bukan leader. Anggapan yang timbul dalam pendekatan ini adalah bahwa leader dilahirkan dan bukan dibuat. Kedua, behavioral theories (pendekatan perilaku) berusaha menentukan apa yang dilakukan para leader efektif. Pendekatan ini memusatkan perhatiannya pada dua aspek perilaku kepemimpinan yaitu fungsi kepemimpinan (fungsi task-related dan group maintenance) dan gaya kepemimpinan (task-oriented dan employee-oriented). Dalam era selanjutnya, disadari bahwa tidak ada satupun style leadership yang terbaik dan berlaku universal untuk segala situasi dan lingkungan. Beberapa teori terkenal dalam kelompok pendekatan ini antara lain teori X dan Y (Douglas McGregor), Ohio State Studies (initiating structure dan consideration), University of Michigan Studies (employee-oriented leader dan production-oriented leader), the managerial grid, dan Scandinavian studies. Ketiga, contingency theories (pendekatan situasional) menekankan bahwa gaya leadership yang digunakan tergantung pada faktor-faktor situasi, karyawan, tugas, organisasi, dan variabel lingkungan lainnya. Teori situasional yang banyak diadopsi antara lain Fiedler Model, Hersey and Blanchard's Situational Theory, Leader-Member Exchange Theory, Path-Goal Theory, dan Leader-Participation Model.

\section{PENDEKATAN TERBARU LEADERSHIP}

Dalam dekade terakhir, lingkungan bisnis mengalami perubahan yang sangat dramatis. Implikasinya, muncul kebutuhan konsep leadership "baru" untuk menghadapi perubahan lingkungan yang terus berlangsung. Terdapat tiga pendekatan terbaru leadership. Pertama, charismatic leadership yang mengemukakan bahwa para pengikut membuat atribusi (penghubungan) dari kemampuan leadership 
yang heroik atau luar biasa bila mereka mengamati perilaku tertentu. Kedua, transactional dan transformational leadership. Transactional leader adalah leader yang memandu atau memotivasi pengikut mereka dalam arah tujuan yang ditegakkan dengan memperjelas peran dan tuntutan tugas, sedang transformational leader adalah leader yang memberikan pertimbangan dan rangsangan intelektual yang diindividualkan dan yang memiliki karisma. Ketiga, visionary leadership yaitu kemampuan untuk menciptakan dan mengartikulasikan visi masa depan organisasi yang realistik, kredibel, dan menarik (Robbins, 2001).

Kepemimpinan transformational didefinisikan sebagai kepemimpinan yang mencakup upaya perubahan organisasi (sebagai lawan kepemimpinan yang dirancang untuk mempertahankan status quo). Diyakini bahwa gaya ini akan mengarahkan pada kinerja superior dalam organisasi yang sedang menghadapi tuntutan pembaharuan dan perubahan. Seorang pemimpin dapat mentransformasikan bawahannya melalui empat cara yang disebut Empat I (Bass dan Avolio, 1994) yaitu:

1. Idealized Influence. Pemimpin transformational memberikan contoh dan bertindak sebagai role model dalam perilaku, sikap, maupun komitmen bagi bawahannya. la sangat memperhatikan kebutuhan bawahannya, menanggung risiko bersama, tidak menggunakan kekuasaannya untuk kepentingan pribadi, memberi visi dan sense of mission, dan menanamkan rasa bangga pada bawahannya.

2. Inspirational Motivation. Pemimpin transformational memotivasi dan menginspirasi bawahannya dengan jalan mengkomunikasikan ekspektasi tinggi secara jelas, menggunakan berbagai simbol untuk memfokuskan usaha atau tindakan, dan mengekspresikan tujuan penting dengan cara-cara sederhana.

3. Intellectual Stimulation. Pemimpin transformational berupaya menciptakan iklim yang kondusif bagi berkembangnya inovasi dan kreativitas. Perbedaan pendapat dipandang sebagai hal yang lumrah terjadi.

4. Individualized Consideration. Pemimpin transformational memberikan perhatian khusus terhadap setiap kebutuhan individual untuk berprestasi dan berkembang, dengan jalan bertindak sebagai pelatih (coach) atau penasehat (mentor).

\section{VISIONARY LEADERSHIP DAN TRANSFORMATIONAL LEADERS}

Kotter (1996) menyatakan bahwa visi adalah komponen sentral dari kepemimpinan yang hebat (great leadership). Visi adalah gambaran tentang masa depan yang diinginkan oleh pemimpin tentang organisasi yang dipimpinnya, disertai penjelasan secara implisit atau eksplisit tentang mengapa orang-orang harus berusaha bersama menciptakan masa depan yang diinginkan itu. Bila masa depan yang diinginkan harus dicapai melalui sebuah perubahan fundamental dalam organisasi yang dipimpinnya, sebuah visi yang tepat dan baik akan membantunya 
dalam tiga hal penting: (1) visi akan menjelaskan arah perubahan yang diinginkan secara gamblang, jelas, dan tegas, (2) visi akan mendorong dan memotivasi orang untuk bergerak ke arah yang benar walaupun langkah-langkah awal mungkin akan menyakitkan bagi mereka, dan (3) visi akan membantu mengkoordinasikan tindakan orang-orang yang berasal dari bidang-bidang yang berbeda, yang jumlahnya bias ratusan, ribuan, atau lebih dengan kecepatan dan efisiensi yang sangat mengagumkan.

Ruky (1997) menyatakan bahwa visionary leaders adalah pencipta dan pembangun sebuah fajar yang baru dalam kehidupan sebuah organisasi. Mereka bekerja menggunakan imajinasi dan keberanian untuk melakukan terobosan dan menjanjikan sebuah tantangan yang akan merangsang orang-orang yang terbaik dan mengumpulkannya untuk bekerja sama mencapai tujuan yang disepakati bersama. Literatur baru tentang kepemimpinan sebenarnya lebih banyak menggunakan sebutan transformational leaders daripada visionary leaders. Seorang transformational leader selalu mempunyai visi yang kuat mengenai gambaran tentang bentuk organisasinya di masa depan bila semua tujuan utamanya telah dicapai. Dengan demikian seorang transformational leader haruslah juga seorang visionary leader. Kebalikan dari seorang transformational leader adalah seorang transactional leader. la lebih tepat disebut sebagai manajer yang selalu berusaha melakukan pekerjaan dengan benar (doing things right). Ciri khas seorang transactional leader adalah hubungannya dengan anak buah yang didasarkan pada asas "masing-masing untung".

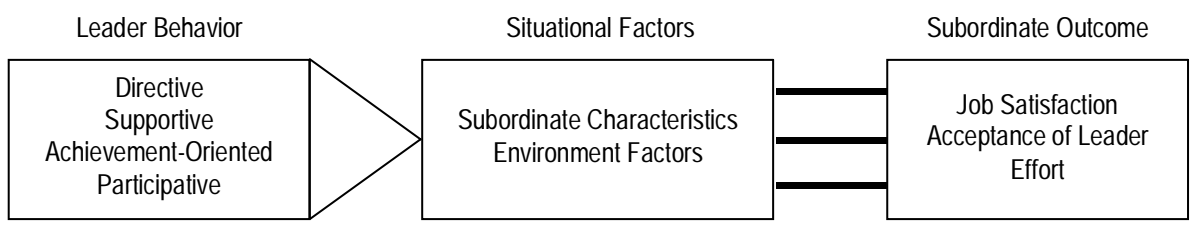

Gambar 1: Path-Goal Theory of Leadership

Transformational leadership berbeda dari transactional dalam dua hal. Pertama, meskipun transformational leader yang efektif juga mengakui kebutuhan dan tujuan kini follower, mereka berbeda dari active transactional leader atas derajat yang mereka usahakan untuk meningkatkan kebutuhan follower (Avolio et al, 1988). Kedua, transformational leadership juga berbeda dari active transactional atas derajat yang leader usahakan untuk mengembangkan follower menjadi leader. Satu tujuan transformational leadership adalah memperbaiki kemampuan follower untuk menyelesaikan masalahnya sendiri dan masalah orang lain. 


\section{MENTERJEMAHKAN VISI}

Bagi seorang leader, memiliki visi saja tidak cukup. Diperlukan kemampuan lain yang juga sangat penting yaitu menerjemahkan visi tersebut sehingga dapat dimenegrti dan dilaksanakan oleh seluruh anggota di dalam organisasi tersebut. Visi ini menjawab pertanyaan "where". Visi yang merupakan arah dari suatu organisasi dapat diterjemahkan menjadi dua bagian yaitu values (nilai-nilai) dan critical success factor (factor-faktor yang penting bagi kesuksesan).

Bagian pertama dari visi ini adalah critical success factors. Ini adalah hal-hal yang memberikan kesempatan paling besar untuk mencapai visi suatu organisasi yang didorong oleh tuntutan pelanggan dan kompetisi pasar. Critical success factors yaitu factor-faktor yang penting untuk kesuksesan ini kemudian diturunkan lagi menjadi rencana bisnis (business plan) dan kemudian diturunkan lagi menjadi key result area dan objective bagi masing-masing orang di dalam organisasi. Sedangkan bagian kedua dari visi adalah values yaitu sikap, pikiran, dan keyakinan yang menentukan perilaku. Values ini adalah seperangkat nilai-nilai yang berusaha untuk dicapai bersama. Values kemudian diturunkan lagi menjadi dimensi yang merupakan perilaku-perilaku yang dibutuhkan untuk menyelesaikan suatu aktivitas.

\section{TIPE DAN KARAKTERISTIK LEADERSHIP}

Secara umum leadership merupakan suatu proses untuk mempengaruhi unit organisasi mencapai tujuannya. Tipe yang mengarah pada gaya/tingkah laku leadership dikategorikan dalam dua istilah yaitu kepemimpinan transaksional (transactional leadership) dan kepemimpinan transformasional (transformational leadership). Transactional leader adalah pemimpin yang menentukan apa yang perlu dikerjakan subordinate untuk mencapai tujuan, mengklasifikasikan tuntutan tersebut, dan membantu subordinate menjadi percaya diri bahwa mereka dapat mencapai sasarannya dengan menambah usaha yang dibutuhkan (Stoner, 1996).

Berkaitan dengan isu perubahan, kita dapat melihat lebih jauh bahwa para transactional leader cocok untuk era ketika pasar sedang berkembang dan persaingan belum tajam. Tipe leadership semacam ini tidak sesuai dengan era perubahan lingkungan yang terjadi secara dramatik. Sedangkan transformational leader menyangkut perubahan, inovasi serta kompetensi kewirausahaan dalam arti kemampuan mengenali peluang usaha. Para transformational leader didefinisikan sebagai agen perubahan dan mempunyai visi yang kuat.

Visi diperlukan sebagai pemicu perubahan ke arah yang lebih baik. Organisasi yang dapat bertahan hidup (survive) dan berkembang (growth) adalah organisasi yang memiliki leader yang bervisi akan perubahan yang sangat tajam sehingga mampu mentransformasikan kapabilitas organisasi untuk membangun daya 
saing perusahaan (Kotter, 1996). Di samping visi, dalam rangka memberikan petunjuk, seorang leader juga harus memiliki sifat dan kualitas "jujur", "melihat ke depan", "menyemangati", dan "kompeten". Karakteristik ini merupakan sumber kredibilitas pribadi yang merupakan kepercayaan orang lain terhadap leader. Leader masa depan harus melihat hubungan perseorangan dengan lebih memberikan perhatian pada perlakuan masing-masing individu di unit organisasi, sekaligus memberikan bimbingan dan nasehat.

Seorang leader juga harus menunjukkan kepada orang lain keteladanan yang diyakini. Memimpin dengan keteladanan adalah melalui bagaimana leader membuat visi dan nilai serta mewujudkannya. Tidaklah cukup bagi leader hanya sekedar mengumandangkan visi yang cemerlang, tetapi leader juga harus muncul, memberi perhatian, dan ikut serta secara langsung dalam proses pencapaian visi. Akhirnya seorang leader harus berani, dalam arti mampu mengambil sikap, mampu memikul risiko, mampu berdiri tegak menghadapi status quo demi kepentingan organisasi yang lebih besar.

\section{PERAN LEADER}

Seorang leader ibarat nahkoda kapal yang mampu menemukan arah dan tujuan kapal berlayar. Arah dan tujuan yang ditentukan harus jelas dan selanjutnya dikomunikasikan kepada awak kapal. Sang nahkoda memikirkan pula tantangan yang mungkin terjadi dan perlu diantisipasi oleh awak kapal. Ketika kapal dilanda kemelut entah karena terjebak dalam pelayaran sesat atau ketika kapal menghadapi badai, peran si nahkoda sebagai leader akan semakin dituntut.

Sebagai seorang nahkoda, tugas seorang leader yang paling penting adalah bagaimana menciptakan suatu visi yang jelas, efektif, dan efisien. Visi tersebut dirumuskan berdasarkan refleksi atas pengalamannya, maupun kemungkinan implementasinya di pasar. Visi dan strategi yang telah dirumuskan leader, pada tataran manajemen, diikuti dengan perencanaan dan penentuan anggaran yang efisien. Masalahnya, seringkali leader dalam setiap organisasi hanya sibuk menyusun perencanaan dan anggaran, namun tidak memiliki visi dan strategi yang jelas.

Selain hal-hal yang mempengaruhi leader di atas, environmental factors juga mempengaruhi hubungan antara leader dan subordinate di luar effort/action. Faktor-faktor tersebut adalah sebagai berikut:

1. Economic Factors

a. Economic Stability

b. Organization of central banking system

c. Existence of capital markets

2. Political and Legal Factors 
a. Quality, efficiency, and effectiveness of legal structure

b. Effect of defense policy

c. Degree of governmental control of business

3. Educational Factors

a. Literacy rate

b. Extent and degree of formal education and training systems

c. Extent and degree technical training

d. Extent and quality of management developmental programs

4. Sociological Factors

a. Social attitude toward industry and business

b. Cultural attitude toward authority and persons in subordinate positions

c. Cultural attitude toward productivity and achivement (work ethic)

\section{INFORMASI ASIMETRI DAN PERILAKU OPORTUNIS LEADER DAN SUBORDINATE}

Angka akuntansi diharapkan dapat berperan untuk meminimalkan konflik kepentingan antara pihak-pihak yang berkepentingan dengan perusahaan [Jensen dan Meckling (1976), Watts (1977), dan Watts dan Zimmerman (1986)]. Namun, sebagaimana kita ketahui, akuntansi yang kita kenal melibatkan management discretion. Hubungan antara leader dan subordinate biasanya berada dalam situasi informasi asimetri atau ketidakseimbangan informasi (asymmetrical information).

Subordinate mempunyai lebih banyak informasi mengenai kapasitas diri, lingkungan kerja, dan perusahaan secara keseluruhan daripada leader. Berdasarkan asumsi bahwa individu-individu bertindak untuk memaksimalkan kepentingan dirinya sendiri, maka dengan informasi asimetri yang dimilikinya akan mendorong subordinate untuk menyembunyikan beberapa informasi asimetri yang tidak diketahui leader. Misalnya dalam hal partisipasi anggaran. Subordinate sengaja membuat anggaran yang mudah dicapai di bawah performance yang dapat diharapkan dari mereka, sehingga ketika subordinate dievaluasi maka subordinate dapat mencapai target yang dianggarkan (Schift dan Lewin, 1970 dalam Hartono dan Riyanto, 1997).

Begitu juga dalam meyusun pelaporan keuangan, subordinate juga memliki informasi asimetri sehingga subordinate dapat lebih fleksibel mempengaruhi pelaporan keuangan untuk memaksimalkan kepentingannya. Cara yang dapat dilakukan subordinate untuk mempengaruhi angka akuntansi yaitu dengan manajemen laba.

IMPLIKASI PADA RISET AKUNTANSI

Secara umum hubungan antara agency theory dan leadership theory dapat dilihat pada gambar 3 dibawah. 
Berdasarkan analisis di atas, riset di bidang akuntansi yang mungkin dapat dilakukan adalah:

1. Menguji hubungan antara gaya kepemimpinan dengan kinerja.

2. Menguji hubungan antara kompensasi dengan kepuasan dan kinerja.

3. Menguji pengaruh penerapan leadership transformational pada agency cost.

4. Menguji pengaruh gaya kepemimpinan, karakteristik subordinate, dan ketidakpastian lingkungan pada kepuasan dan prestasi.

5. Menguji pengaruh budaya pada pemilihan gaya kepemimpinan.

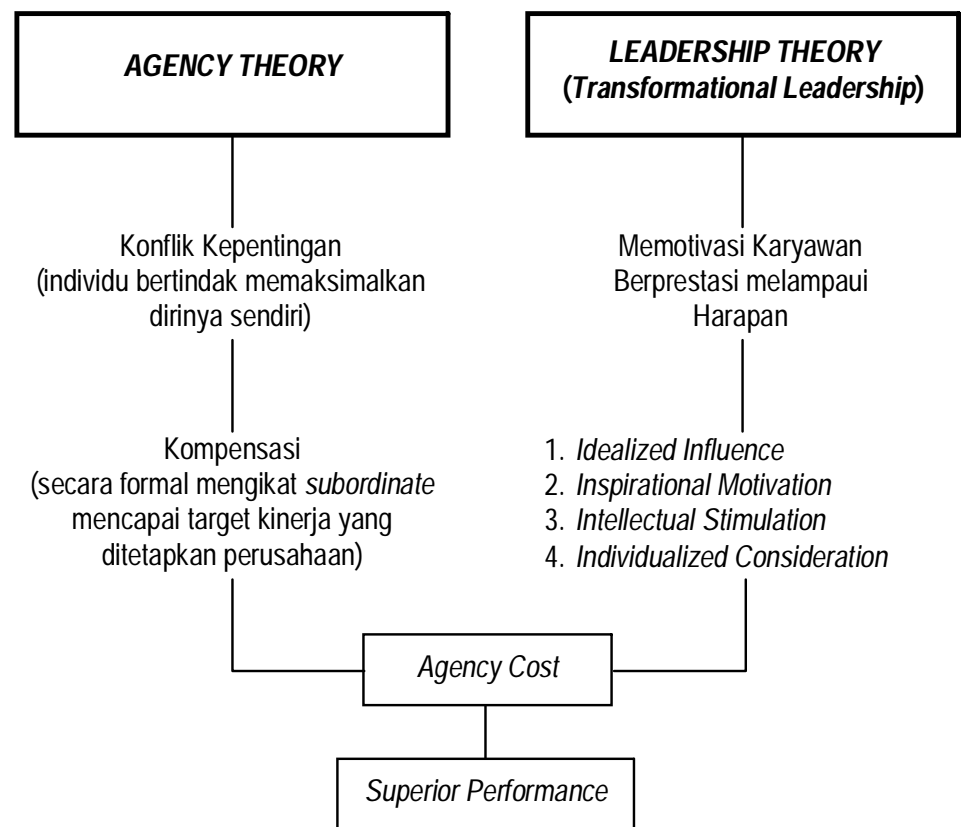

Gambar 3: Hubungan Agency Theory dan Leadership Theory

Di samping itu hubungan antara gaya kepemimpinan dengan kepuasan dan prestasi dapat dikemukakan sebagai berikut: 


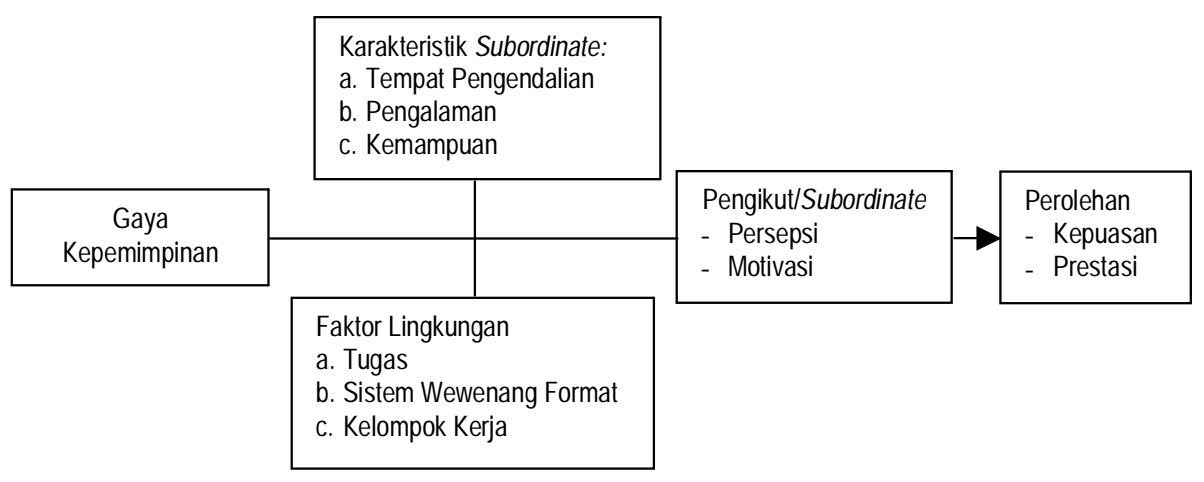

Gambar 4:Hubungan Gaya Kepemimpinan dengan Kepuasan dan Prestasi

\section{EMPIRICAL THEORY}

Seltzer dan Bass (1990) menguji apakah skala transformational akan menambah variance dari outcome measures yang dijelaskan oleh initiation dan consideration. Hasil hierarchical regression menggunakan respon 138 subordinates mengenai 55 manajer menunjukkan bahwa meskipun initiation dan consideration telah mendominasi pengukuran leadership behavior dimasa lalu, temuan studi mendukung pentingnya transformational leadership untuk prediksi yang lebih baik dan memahami leadership. Sedangkan Howell dan Avolio (1993) menguji apakah transformational leadership behavior memprediksi performance unit yang terkonsolidasi untuk periode lebih dari 1 tahun sewaktu mempertimbangkan support untuk inovasi sebagai sebuah moderator.

Selanjutnya Barling dan Weber (1996) menguji pengaruh transformational leadership training pada attitudinal dan financial outcomes. Hasil multivariate analysis of covariance (dengan skore pretest sebagai covariate) menunjukkan bahwa training menghasilkan pengaruh yang signifikan pada persepsi subordinates dari transformational leadership, komitmen organisasi, dan dua aspek financial performance branch-level. Akhirnya Keller (1992) menguji transformational leadership kaitannya dengan performance dari kelompok proyek research and development. Hasil studi menyarankan bahwa leader yang efektif dalam kelompok proyek R\&D cenderung memberikan inspirasi mengenai misi dan tujuan pentingnya pekerjaan yang dilakukan, menstimulasi cara pemikiran baru dan problem solving serta mendukung anggota group melakukan lebih daripada yang diharapkan secara normal. 


\section{KESIMPULAN}

Makalah ini menunjukkan teori agency yang diterapkan pada akuntansi manajemen dengan mengkonsentrasikan pada bagaimana statistik akuntansi manajemen dapat digunakan secara optimal untuk mengontrol perilaku subordinate. Teori agency dapat memprediksi penggunaan dan bentuk pengukuran performance akuntansi manajerial yang diuji dalam praktek. Diharapkan bahwa pendekatan yang diadopsi disini mengakibatkan area penelitian teori agency teknikal dapat mengakses secara lebih mudah terhadap undergraduate audience dan memotivasi audience untuk mempelajari area ini. Paper review klasik dalam area ini meliputi Baiman (1982), Namazi (1985), dan Baiman (1990).

Untuk mengendalikan organisasi di masa mendatang dibutuhkan seorang leader yang mempunyai gaya transformational leadership sebagai agen perubahan dan selalu mempunyai visi yang kuat sehingga mampu membawa organisasi mencapai tujuannya dan memenangkan kompetisi di era globalisasi. Sebagai agen perubahan maka leader harus berciri pembelajar seumur hidup. Sedangkan sebagai visionary leadership, maka leader harus memiliki karakteristik jujur, melihat jauh ke depan, menyemangati, dan kompeten. Di samping itu, leader perlu menunjukkan sikap keteladanan atas apa yang diyakininya. Dengan visi diharapkan leader dapat mengatasi kompleksitas, ketidakjelasan, dan ketidakpastian.

\section{DAFTAR PUSTAKA}

Ashton, D., Hopper, T., dan Scapens, R.W. (1995). Issues in Management Accounting. Second Edition. Prentice Hall.

Avolio, B.J., Waldman, D.A., dan Einstein, W.O. (1988). Transformational Leadership in A Management Game Simulation. Group \& Organization Studies. Vol. 13 No. 1, March: 59-80.

Baiman, S. (1982). Agency Research in Managerial Accounting: A Survey. Journal of Accounting Literature (Spring): 154-213.

. (1990). Agency Theory Research in Managerial Accounting: A Second Look. Accounting, Organizations, and Society (July): 341-372.

Baiman, S. dan Lewis, B. (1989). An Experiment Testing the Behavioral Equivalence of Strategically Equivalent Employment Contracts. Journal of Accounting Research 27 (Spring): 1-20.

Barling, J. dan Weber, T. (1996). Effects of Transformational Leadership Training on Attitudinal and Financial Outcomes: A Field Experiment. Journal of Applied Psychology Vol. 81 No. 6: 827-832. 
Bass, B.M. (1985). Leadership and Performance Beyond Expectations. New York: Free Press.

Bass, B.M. dan Avolio, B.J. (1994). Improving Organizational Effectiveness through Transformational Leadership. Thousand Oaks, CA: Sage.

Burns, J.M. (1978). Leadership. New York: Harper \& Row.

Christie, A. A. dan Zimmerman, J.L. (1994). Efficient and Opportunistic, Choices of Accounting Procedures: Corporate Control Contest. The Accounting Review (Oktober): 539-566.

Eisenhardt, K. (1989). Agency Theory: An Assessment and Review. Academy of Management Journal (14): 57-74.

Gibson, J.L., Ivancevich, J.M., dan Donnelly, J.H. (1991). Organizations: Behavior, Structure, Processes. Homewood, III: Richard D. Irwin, Inc.

Hartono, J. dan Riyanto, B. (1997). The Effect of Asymmetrical Information and Risk Attitude on Incentive Schemes: A contingency Approach. Jurnal Ekonomi dan Bisnis Indonesia. Vol. 12 (1): 1-12.

Healy, P.M. (1985). The Effect of Bonus Schemes of Accounting Decision. Journal of Accounting and Economics (7): 85-107.

Healy, P.M. dan Palepu, K.G. (1993). The Effect of Firm' Financial Disclosure Strategies on Stock Prices. American Accounting Association, Accounting Horizons. Vol. 7 No. 1 (Maret): 1-11.

Howell, J.M. dan Avolio, B.J. (1993). Transformational Leadership, Transactional Leadership, Locus of Control, and Support for Innovation: Key Predictors of Consolidated-Business-Unit Performance. Journal of Applied Psychology Vol. 78 No. 6: 891-902.

Jensen, M.C. dan Meckling, W.H. (1976). Theory of the Firm: Managerial Behavior, Agency Cost, and Ownership Structure. Journal of Financial Economics 3: 305-360.

Jensen, M.C. dan Murphy, K.J. (1990). Performance Pay and Top-Management Incentives. Journal of Political Economy 98: 225-264.

Keller, R.T. (1992). Transformational Leadership and The Performance of Research and Development Project Groups. Journal of Management Vol. 18 No. 3: 489-501.

Kotter, J.P. (1996). Leading Change. Harvard Business School Press. Boston. MA. 
Kreitner, R. dan Kenicki, A. (1992). Organizational Behavior. Homewood, III: Richard D. Irwin, Inc.

Lambert, R. dan Larcker, D. (1987). An Analysis of The Use of Accounting and Market Measures of Performance in Executive Compensation Contract. Journal of Accounting Research, Supplement: 85-125.

Namazi, M. (1985). Theoretical Development of Principal-Agent Employment Contracts in Accounting: The State of The Art. Journal of Accounting Literature 4 (Spring): 113-163.

Robbins, S.P. (2001). Organizational Behavior. Prentice Hall International, Inc.

Ruky, A.S. (1997). Penerapan "Visionary Leadership" dalam Perusahaan Indonesia: Suatu "Conditiosine Quanon" untuk Menyongsong Millenium Ketiga. Usahawan No. 09 Th. XXVI September 1997.

Seltzer, J. dan Bass, B.M. (1990). Transformational Leadership: Beyond Initiation and Consideration. Journal of Management Vol. 16 No. 4: 693-703.

Stoner, J.A.F., Freeman, R.E., dan Gilbert, D.R. (1995). Management. Pentice-Hall, Inc., New Jersey.

Supriyono. (1997). Akuntansi Biaya dan Akuntansi Manajemen untuk Teknologi Maju dan Globalisasi. BPFE Yogyakarta: 19-20.

Watts, R.L. (1977). Corporate Financial Statements: A Product of the Market and Political Processes. Australian Journal of Management (2): 53-75.

Watts, R.L. dan Zimmerman, J.L. (1986). Positive Accounting Theory. Prentice Hall. Englewood Cliffs. New Jersey 07632.

Wolk, H.I., Francis, J.R., dan Tearney, M.G. (1992). Accounting Theory: A Conceptual \& Institutional Approach. College Division. South-Western Publishing Co.

Wren, J.T. (1995). The Leader's Companion. New York: The Free Press.

Yulk, G.A. (1989). Leadership in Organizations. Englewood Cliffs: Prentice-Hall. 